\title{
AKT Inhibitor ARQ 092
}

National Cancer Institute

\section{Source}

National Cancer Institute. AKT Inhibitor ARQ 092. NCI Thesaurus. Code C99172.

An orally bioavailable inhibitor of the serine/threonine protein kinase AKT (protein kinase

B) with potential antineoplastic activity. AKT inhibitor ARQ 092 binds to and inhibits the activity of AKT in a non-ATP competitive manner, which may result in the inhibition of the PI3K/AKT signaling pathway. This may lead to the reduction in tumor cell proliferation and the induction of tumor cell apoptosis. The AKT signaling pathway is often deregulated in cancer and is associated with tumor cell proliferation, survival and migration. 